\title{
Radio and Nuclear Pharmacy Education \& Practice Needs Exploration in India
}

\section{RESPECTED SIR,}

Greetings, we write this letter as our perception on education of radio and nuclear pharmacy after completion of our project at Nuclear Medicine Department, Civil hospital, Ahmadabad, Gujarat.

Pharmacy education faces the challenge of incorporating an increasing number of specialized areas of practice into the curriculum. The desire to train competent generalists should be balanced against the need for students to graduate with knowledge of relatively specialization. Depending on the training of faculty, financial conditions, and time constraints within a Pharmacy college, specialty areas may be omitted from the curriculum. An example of one such specialty practice area is nuclear pharmacy practice. Use of radio and nuclear pharmacy was started in 1900 and propelled after invention of ${ }^{99} \mathrm{Tc}$ generator. ${ }^{1}$ In such challenging development pharmacist fill vacuum and expand professional service. In 1975, in west especially USA, the American Association of Colleges of Pharmacy (AACP) ${ }^{2}$ approved a resolution advocating that all schools of pharmacy provide education in nuclear pharmacy practice to their students. From 1978, nuclear pharmacy became the first specialty recognized by the board of pharmaceutical specialty in turn accept and open a horizon of nuclear pharmacy / nuclear pharmacist. To strive hard on the value, AACP in $1981^{3}$ and in $1996^{4}$ surveyed the status of radio and nuclear pharmacy. 63 of 72 offered some lectures, instruction in radio and nuclear pharmacy widely ranged from no instruction to doctor of Philosophy (Ph.D.) and 58 of 84 colleges do offer came to know. Contrarily and conversely, such studies are not carried out and published Indian pharmacy education.

From 1937 to 1991, Indian pharmacy curriculum was industry oriented, till today too. Graduate course is more industry oriented than the health care oriented. In 1991, pharmacy council of India reframes education regulation and modifies course contents and subjects. New additions and overall restructuring added stress on professional orientation of pharmacist. ${ }^{5}$ Moreover, education of clinical pharmacy at postgraduate level in 1996 and introduction of Pharm. D. in $2008^{6}$ expand the horizon of pharmacy service. But if we carefully look inside the syllabi of pharmacy, radio and nuclear pharmacy is one of the study areas remain uncovered \& unexplored not only in hospital and clinical pharmacy but also in pharmaceutical and medicinal chemistry too. Most of time classroom teaching of this topic is limited to theoretical aspects. At the same time less importance is being given to such practice area in most of pharmacy colleges resulting in creation of poor interest and creativeness among pharmacy students. Published article on pharmacy service focuses pharmaceutical care and study on routine and daily activity of clinical pharmacist while on the special service-like radio and nuclear pharmacy- merely scarce. Finding a reason will be worth noting. Attempt has been made by pharmacist authors, to upgrade radio and nuclear pharmacy, by publishing article in national and international journal, but these articles are limited to review and over view. ${ }^{7-9}$ Research, practical, education and service of radio and nuclear pharmacy in Indian pharmacy colleges are in infancy in real sense. Moreover, radio and nuclear medicine is important branch of medical science developed well in India. ${ }^{10}$ Medical physicians and radiologist play a significant role in the overall health care. Radiation safety office is responsible for ensuring safe use of radio and nuclear medicine. It is evident the safe practice of radiation is depends on trained staff in respective field. Therefore, pharmacist is nowhere in picture. Pharmacist by profession and education is expert of medicine and qualify to render professional service. One of the reasons may be employment unawares and lack of proper education. Therefore, students on many circumstances essentially prepare and expose in this area. In 2013, Bhabha Atomic Research Centre (BARC) announced recruitment and invited application for pharmacist. It was 6 vacant pharmacist "B" post. Payable emolument was approximately total Rs.25699/-. The qualifica- 
tion was D.Pharm., with/\& registered pharmacist only and focused traditional job responsibility and working of pharmacist. ${ }^{10}$ Attempt must be necessary to grab employment opportunity in this area. Contrarily, Education in Pharmacy College must also meet the knowledge and skill requirement to prepare pharmacist in this area.

Inadequate applied concept of radio and nuclear pharmacy in undergraduate (B.Pharm. and D.Pharm.) and postgraduate (M.Pharm; Pharmacy Practice, Clinical Pharmacy) accelerates many problems with lack of practical and real techniques in such area. It make us arrive to conclude that many budding Pharmacist know little on applied aspects of radio and nuclear pharmacy, its application, clinical and therapeutic application, quality assurance, employment and remuneration, future prospect, contribution \& work-role of radio \& nuclear

\section{REFERENCES}

1. Wolf W, Tubis M. Radiopharmaceutical. In Eric W Martin. Dispensing of Medication. $7^{\text {th }}$ edn, Pennsylvania; Mack Publishing Company; 1971. P 1058.

2. Schlegel J, Shaw S. Nuclear pharmacy education. Am Pharm. 1981; NS21: 38-9.

3. Penna R. Pharmacy's first specialty. Am Pharm. 1982; NS22: 612-5.

4. Heske SM, Hladik WB, Laven DL, Kavula MP. Status of radiologic pharmacy education at colleges of pharmacy. Am J Pharm Educ. 1996; 60(2): 152-61.

5. Singh H. Pharmaceutical education: in history of pharmacy in India and related aspects. Diplomatic training, New Delhi: Vallabh Prakashan; 1998. P. 52-76. pharmacist in the management of patients and real health care setting. Nuclear pharmacists serve as vital links in the provision of nuclear medicine services. By working closely with the nuclear medicine staff, nuclear pharmacists can contribute a tremendous amount to the provision of care for the patients who are undergoing nuclear medicine procedures. While similar to traditional pharmacy, nuclear pharmacy is also in many ways unique, and can be a challenging and rewarding career choice for pharmacists.

It is worth noting that in present time, admission and placement status of pharmacy colleges tell a different story. In such recession time, education and practice of radio and nuclear pharmacy may provide opportunity and employment; "Doors are closed but not yet locked"

6. Hariharan S, Sankar V, Ramanathan M. the road ahead for the Pharam D programme in India. Introduction of Pharm. D. d in India. Pharma Times. 2012; 44(9): 17-9.

7. Vikrant Verma. Nuclear Pharamcy: an updated review. IJPRD. 2011; 3(6): 218-25.

8. Patidar AK, Patidar P, Tandel TS, Mobiya A, Selvam G, Jeyakandan M. Current Trends In Nuclear Pharmacy Practice. International Journal of Pharmaceutical Sciences Review and Research 2010; 5(2): 145-51.

9. Samuel AM. Growth of nuclear medicine. Def Sci J. 1990; 40(4): 335-46.

10. Govt. of INDIA. ADVERTISEMENT NO. 01/2013(R-II), Available \& assessed on URL: http://barc.gov.in. Assessed in February 2013.

\section{Patel Jyoti Pravin Kumar, Bhatt Sandip Kumar Prakash Kumar}

Department of Pharmacology \& Clinical Pharmacy, K.B. institute of Pharmaceutical Education and Research, Gh-6, Sector -23, Gandhinagar, Gujarat, India. Email: sunrisedeep78@rediffmail.com DOI : 10.5530/ijopp.7.4.11 